\title{
Could Preference for Palatable Foods in Neonatally Handled Rats Alter Metabolic Patterns in Adult Life?
}

\author{
CARLA DA S. BENETTI, PATRÍCIA P. SILVEIRA, ANDRÉ K. PORTELLA, LUISA A. DIEHL, EDELVAN NUNES, \\ VANESSA S. DE OLIVEIRA, CARLA DALMAZ, AND MARCELO Z. GOLDANI
}

\author{
PPG Pediatrics [C.S.B., M.Z.G.], Department of Biochemistry [C.S.B., P.P.S., A.K.P., L.A.D., E.N., V.S.O., C.D.], Department of \\ Pediatrics [M.Z.G.], Instituto de Ciências Básicas da Saúde, UFRGS, 90035-003 Porto Alegre, Rio Grande do Sul, Brazil; PPG \\ Neurosciences [P.P.S., A.K.P., C.D.], Instituto de Ciências Básicas da Saúde, UFRGS, 90046-900 Porto Alegre, Rio Grande do Sul, Brazil
}

\begin{abstract}
Previous studies indicate that, in adulthood, neonatally handled rats consume more sweet food than nonhandled rats. The aim of the present study was to assess the effects of the chronic exposure to a palatable diet (chocolate) in adult neonatally handled rats. We measured the consumption of foods (standard lab chow and chocolate), body weight gain, abdominal fat deposition, and levels of plasma lipids, glucose, insulin, and corticosterone in adult neonatally handled (10 min/d, first $10 \mathrm{~d}$ of life) and nonhandled rats. We found an increased intake of chocolate in handled rats, but this consumption decreased over time. Handled male animals exhibited higher body weight, higher caloric efficiency, and lower triglyceride levels. Nonhandled females that were exposed long-term to the highly caloric diet had increased abdominal fat deposition compared with handled females. Overall female rats had increased abdominal fat deposition, higher total cholesterol and glucose levels, and lower insulin in comparison with males. Interestingly, chocolate consumption diminished the weight of the adrenal glands in both handled and nonhandled animals. These findings suggest that neonatal handling induces a particular metabolic pattern that is sex specific. (Pediatr Res 62: 405-411, 2007)
\end{abstract}

$\mathrm{M}$ other-infant interactions have an important influence on the programming of both behavioral $(1,2)$ and metabolic patterns $(2,3)$ in the offspring, which can last into adulthood. In mammals, the mother is the main environmental stimulus and provider for the infant, and maternal care has profound, long-lasting intergenerational effects in rats $(4,5)$ and humans (6).

Some experimental approaches have been developed to study this interaction. One of them is neonatal handling, a brief, repeated, and apparently innocuous separation from the mother in the neonatal period. Neonatal handling modulates the development of the hypothalamopituitary-adrenal axis (HPA) axis and is associated in adulthood with decreased stress reactivity $(7,8)$ and increased ingestion of palatable food $(9)$.

Glucocorticoids are implicated in the development of eating disorders $(10,11)$; they modulate in part the salience of palatable food intake and influence abdominal fat distribution (12).

Received December 7, 2006; accepted May 2, 2007.

Correspondence: Carla da S. Benetti, Ph.D., Departamento de Bioquímica, ICBS, UFRGS, Ramiro Barcelos, 2600 (Anexo) Lab. 11, 90035-003, Porto Alegre, RS, Brazil; e-mail: carlabenetti@yahoo.com.br

CNPq, CAPES, and FAPERGS-PRONEX supported this study.
In addition, chronic glucocorticoid exposure is associated with several features of metabolic syndrome (13-15). Because neonatal handling leads to a differential functioning of the HPA axis and also affects feeding behavior, it is possible that these rats may exhibit special adaptations in the face of specific challenges, such as long-term exposure to a hyperpalatable diet.

The aim of this study was to verify the effects of a long-term exposure during adulthood to a highly palatable, highly caloric diet (chocolate) in neonatally handled rats. Food consumption, body weight, and abdominal fat distribution were measured. Blood plasma was assayed for glycemia, plasma insulin, lipids, and corticosterone levels. Our hypothesis was that neonatal handling is associated with a differential pattern of feeding and weight gain and possibly particular metabolic adaptations to this type of diet.

\section{METHODS}

Subjects. Pregnant Wistar rats bred at our animal facility were randomly selected. Animals were single-housed and maintained in a controlled environment with food and water provided ad libitum. All litters were culled within $24 \mathrm{~h}$ of birth to eight pups and maintained intact except for handling procedures, which were carried out between 0900 and $1100 \mathrm{~h}$. The researcher changed gloves between manipulations of each litter to avoid the spread of any kind of odor from nest to nest.

The day of birth was considered as d 0. Litters were weaned and separated by sex on postnatal d 21. Two male and female pups were used per litter per group. After weaning, rats were housed four to five per cage. Eighty-three rats were used in the different experiments, derived from 25 different litters. The number of animals used was estimated from previous experiments $(9,16)$, in which neonatally handled rats eat approximately $60 \%$ more palatable food than controls. Considering the SD of $0.6 \mathrm{~g}$ drawn from these studies, using a significance level of $5 \%$, and power of $80 \%$, we came to the number of cages we had to evaluate consumption. For the other variables, we established a possible difference of $20 \%$ between the groups, estimating a SD similar to previous studies (16), again with a significance level of $5 \%$ and power of $80 \%$. All animal procedures were approved by the Institutional Ethical Committee (Ethical Committee, UFRGS).

Neonatal handling model. In the nonhandled group, pups were left undisturbed with the dam until weaning. Routine cage cleaning was suspended during this period.

In the handled group, this procedure was carried out as described previously (9). The dam was gently pulled to one side of the cage, and the pups were removed from their home cage and placed into a clean cage lined with clean paper towels. The litter was then placed in an incubator set to maintain an ambient temperature of $30-32^{\circ} \mathrm{C}$ (warm water at $34^{\circ} \mathrm{C}$ ). After $10 \mathrm{~min}$, pups were returned to their dams. This procedure was performed from $\mathrm{d} 1$ to 10 after birth, and pups were then left undisturbed until postnatal d 21 .

Abbreviation: HPA, hypothalamopituitary-adrenal axis 
Table 1. Macronutrient composition of the diets per $100 \mathrm{~g}$ of food used in the study

\begin{tabular}{lccccc}
\hline \multicolumn{1}{c}{ Food } & Kcal & CHO $(\mathrm{g})$ & Protein $(\mathrm{g})$ & Fat $(\mathrm{g})$ & Fiber $(\mathrm{g})$ \\
\hline Standard rat chow & 290 & 56 & 22 & 4.5 & 4.92 \\
Chocolate & 544 & 64 & 4.4 & 30.4 & 0 \\
\hline
\end{tabular}

CHO, carbohydrates.

Habituation to the new food. Starting on d 60 of life, rats were habituated to a novel environment containing the new food. A previously weighed amount of chocolate (milk chocolate, Neugebauer) was placed in one extremity of the box. The animals were habituated to this environment for $5 \mathrm{~d}, 3 \mathrm{~min}$ each day, under food restriction (receiving about $80 \%$ of habitual ingestion). On d 6, the rats were tested for the consumption of palatable food, having received lab chow ad libitum for the previous $24 \mathrm{~h}$. These procedures were performed to verify whether the animals would eat chocolate as they usually ingest other types of palatable food (9), both with and without food restriction. After this habituation period, the animals received rat chow ad libitum.

Long-term exposure to palatable food in the home cage. On the d 83 of life, all animals were weighed and randomized to different same-sex groups that were housed three to four per cage. The groups were subdivided into (1) nonhandled + standard lab chow, $(2)$ nonhandled + chocolate + standard lab chow, (3) handled + standard lab chow, and (4) handled + chocolate + standard lab chow. One week later, specific groups started to receive chocolate ad libitum in the home cage. During $30 \mathrm{~d}$, previously weighed amounts of chocolate and standard lab chow were offered, and the remaining amount was measured each day to evaluate the consumption. The animals were weighed once per week over the course of exposure to this diet. They were then killed by decapitation after $6 \mathrm{~h}$ of fasting. Food consumption was measured per cage and then divided by the number of animals per cage to determine mean consumption per animal. In the statistical analysis of food consumption, $n$ represents the number of cages. Table 1 describes the nutritional composition of the diets used in the study.

Blood collection and abdominal fat dissection. Trunk blood was collected into heparinized tubes for insulin, glucose, total cholesterol, high-density lipoprotein (HDL) cholesterol, triglycerides (TGs), and corticosterone determination. Plasma was separated and frozen at $-20^{\circ} \mathrm{C}$ until the day of analysis.

Adrenal glands were dissected and weighed. The two major portions of abdominal fat (gonadal and retroperitoneal adipose tissue depots) were dissected. Both adrenal and abdominal fat tissues were weighed using a scale with a precision of $0.0001 \mathrm{~g}$.

Biochemical analysis. Plasma was extracted with ethyl acetate, and the extract evaporated and dissolved for corticosterone evaluation using an enzyme-linked immunosorbent assay (ELISA) kit (Cayman Chemical Co., Ann Arbor, MI). Insulin was also measured using ELISA (Alpco Diagnostics, Mercodia AB, Uppsala, Sweden). Plasma glucose was measured by the glucose oxidase method (BioSystems, Barcelona, Spain). Total cholesterol and TGs were measured with commercial kits (Laborclin, Pinhais, PR, Brazil). HDL cholesterol was measured using a kit from Wiener, Rosario, Argentina.

Statistical analysis. Data were expressed as mean \pm SEM and analyzed by two-way, three-way or repeated-measures analysis of variance (ANOVA), followed by the Duncan multiple range test, when indicated. Significance levels for all measures were set at $p<0.05$. Sample size was calculated as described above.

\section{RESULTS}

Chocolate habituation (d 1-5) and test (d 6). During chocolate habituation, there was an increase in the consumption of chocolate over time (repeated-measures ANOVA, $p<$ 0.001, 22-25 per group for males and 15-20 per group for females). There was an effect of group in which neonatally handled rats consumed more than nonhandled rats $(p=$ 0.007). Handled rats also displayed higher increases in their consumption over time in relation to nonhandled rats (interaction between handling and time, $p=0.036$ ) without there being an interaction between gender and time or group. In the test session ( $\mathrm{d}$ 6), males ate more than females (two-way ANOVA, $p=0.023$ ), but there was no effect of group and no interaction. Figure 1 displays these results.

Long-term consumption of standard lab chow and chocolate. Figure 2 displays the consumption of the two diets during the 30-d period. We arbitrarily chose and analyzed the consumption on $\mathrm{d} 1,8,15,22$, and 30 using repeatedmeasures ANOVA, using the mean consumption values from each cage. The groups receiving chocolate decreased their consumption of rat chow (Fig. $2 A, B ; p=0.001$, three to four cages per group), and overall males ate more than females $(p<0.001)$. There was an interaction between time and diet $(p=0.009)$ and time and gender $(p=0.008)$, but no interactions with group.

In the first $24 \mathrm{~h}$ of exposure to chocolate, neonatally handled rats ate more than nonhandled animals (two-way ANOVA, $p=0.044$, three to four cages per group), but there was no effect of gender and no interaction. Handled rats decreased their consumption much more than the nonhandled group did (repeated-measures ANOVA, interaction between time and group, $p<0.001$ ), although all rats decreased their consumption over time $(p<0.001)$. Although all females had a more discrete decrease in chocolate consumption (interaction between time and gender, $p=0.013$ ), nonhandled females decreased their consumption the least (interaction between time, group and gender, $p=0.021$ ). These results are displayed in Figure $2 C$ and $D$.

Food preference. To estimate the preference for chocolate over standard lab chow, we divided the amount of kilocalories derived from chocolate by the total caloric intake. All the groups exhibited a decrease in the preference for chocolate
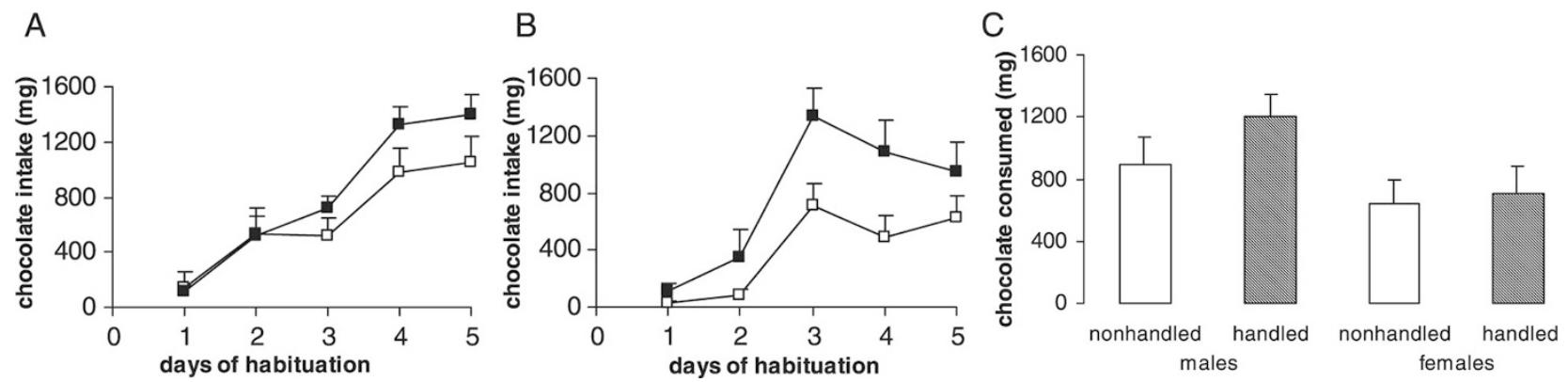

Figure 1. Acute chocolate consumption in adult neonatally handled and nonhandled rats. Nonhandling $(\square)$, handling ( $\square$ ). Repeated-measures ANOVA showed an effect of handling during habituation $(p=0.007)$. Data are expressed as mean \pm SEM. (A) Males' chocolate consumption during habituation, 22-25 per group. (B) Females' chocolate consumption during habituation, 15-20 per group. (C) Chocolate consumed in the test session. Males consumed more than females (two-way ANOVA, $p=0.023$ ). 

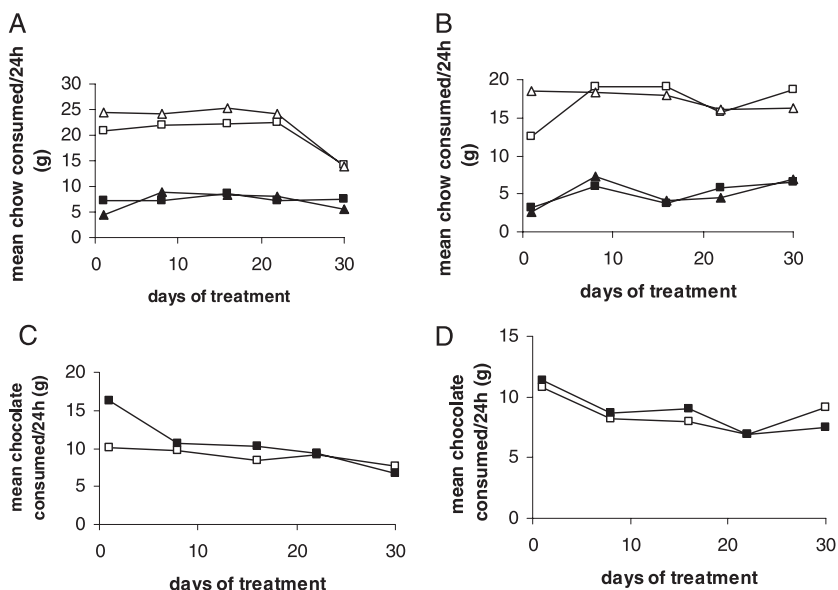

Figure 2. Long-term standard lab chow and chocolate consumption in handled $(\mathrm{H})$ and nonhandled $(\mathrm{NH})$ adult rats. Data are expressed as mean \pm SEM. (A) Mean rat chow consumed in males. $(B)$ Mean rat chow consumed in females. NH chow $(\square)$; NH chocolate $(\square)$; H chow $(\Delta)$; H chocolate $(\boldsymbol{\Delta})$. Repeated-measures ANOVA showed an effect of diet, gender, and interactions between time $\times$ diet and time $\times$ gender $(p<0.01)$. (C) Mean chocolate consumed in males. $(D)$ Mean chocolate consumed in females, three to four cages per group. NH $(\square)$; H ( $\square$ ). Handled males had a more salient decrease in chocolate consumption over time (repeated-measures ANOVA, $p=0.021$ )

over time (repeated-measures ANOVA, $p=0.005$, three to four cages per group), without interactions (Table 2).

Caloric intake. Groups receiving chocolate demonstrated a higher caloric intake compared with the rat chow groups (three-way ANOVA, $p<0.001$, three to four cages per group), and males exhibited an increased caloric consumption $(p<0.001)$, which is not observed if consumption is expressed as kilocalories per gram of body weight. Neonatal handling led to an increased total caloric intake, the value of which almost reached significance $(p=0.055)$ when compared with nonhandled animals (Fig. 3A).

Caloric efficiency. To determine the amount of body weight that was gained as a result of caloric intake, body weight gain in milligrams was divided by the total amount of kilocalories consumed over the $30-\mathrm{d}$ period. We observed that males had a greater caloric efficiency than females (three-way ANOVA, $p=0.003$, three to four cages per group) without there being an effect of group, diet, or interactions. However, when analyzing males separately from females, only neonatally handled males had an increased caloric efficiency $(p=0.050)$ without there being an effect of diet or interactions (Fig. 3B).

Body weight gain. Animals receiving chocolate (three-way ANOVA, $p=0.019$, three to four cages per group) and males $(p<0.001)$ gained the most weight during the 30-d period. There was no effect of group ( $p=0.066$ ) or interactions (Fig. $3 C)$.

As displayed in Figure 4, there was an effect of gender on body weight (repeated-measures ANOVA, $p<0.001,11-13$ per group for males and 7-11 per group for females) because males weighed more than females. Although all groups increased their body weight over time $(p<0.001)$, handled rats (interaction time and group, $p=0.011$ ), those that were exposed to chocolate (interaction time and diet, $p=0.008$ ), and males (interaction time and gender, $p<0.001$ ) gained the most weight. There was an interaction between time, group, and gender $(p=0.012)$, in which handled males exhibited a higher increase in body weight over time. The interaction between group and gender almost reached significance $(p=$ $0.054)$.

Abdominal fat. Abdominal fat deposition is expressed in relation to the body weight of each rat. The groups that ate chocolate had more abdominal fat deposition (three-way ANOVA, $p<0.001,11-13$ per group for males and 9-12 per group for females), which was also higher in females than in males $(p=0.002)$. There was a marginally significant interaction between diet and gender $(p=0.07)$. Interestingly, there was an interaction between the neonatal manipulation, diet, and gender $(p=0.05)$, in which nonhandled females had an increased abdominal fat deposition when exposed to the palatable diet, whereas handled females receiving chocolate were not different from the group receiving rat chow (Fig. 5).

Adrenal glands. Measures of both the ratio between adrenal weight and body weight (data not shown) and absolute adrenal weight values were taken (Fig. 6). In both cases, the consumption of chocolate led to a decrease in adrenal weight (threeway ANOVA, $p<0.02,11-13$ per group for males and 7-11 per group for females). Males had a smaller adrenal glands/ body weight ratio in comparison with the females $(p<0.001)$, and the same result is observed when expressed as absolute values. There was no effect of group $(p>0.1)$, nor were there any interactions.

Plasma lipids levels. Results from biochemical measurements are shown in Table 3. The levels of total cholesterol were higher in the females than in males (three-way ANOVA, $p<0.001,11-13$ per group for males and 7-11 per group for females) without there being any effect of diet $(p=0.467)$, group ( $p=0.070)$, or interactions. Neither group $(p=0.499)$, diet $(p=0.466)$, or gender $(p=0.163)$ had any effect on HDL cholesterol levels. The consumption of chocolate increased TG levels $(p<0.001)$. There was an interaction between group and gender in which nonhandled males had higher TG

Table 2. Chocolate preference of handled and nonhandled rats

\begin{tabular}{clcccrr}
\hline Gender & Group & D 1 & D 8 & D 15 & D 22 & D 30 \\
\hline Males & Nonhandled & $0.72 \pm 0.08$ & $0.71 \pm 0.01$ & $0.66 \pm 0.06$ & $0.70 \pm 0.08$ & $0.68 \pm 0.05$ \\
& Handled & $0.87 \pm 0.03$ & $0.69 \pm 0.04$ & $0.70 \pm 0.04$ & $0.69 \pm 0.02$ & $0.67 \pm 0.05$ \\
Females & Nonhandled & $0.88 \pm 0.04$ & $0.72 \pm 0.02$ & $0.80 \pm 0.05$ & $0.69 \pm 0.03$ & $0.74 \pm 0.06$ \\
& Handled & $0.90 \pm 0.06$ & $0.69 \pm 0.04$ & $0.80 \pm 0.07$ & $0.76 \pm 0.05$ & $0.67 \pm 0.03$ \\
\hline
\end{tabular}

Data are shown as mean $\pm \mathrm{SE}$ of the mean; three to four cages per group. Chocolate preference decreased as the days passed (three-way ANOVA, effect of time, $p=0.005)$. 
A

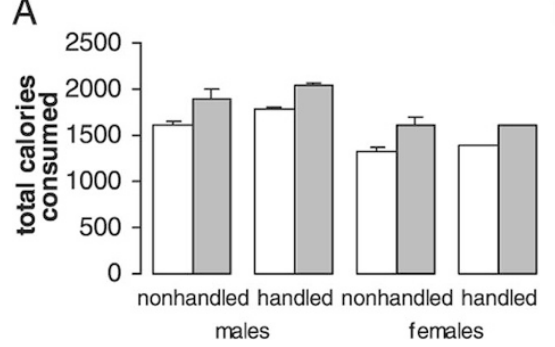

$\mathrm{B}$

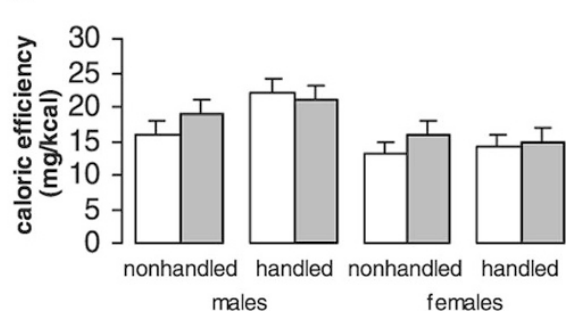

C

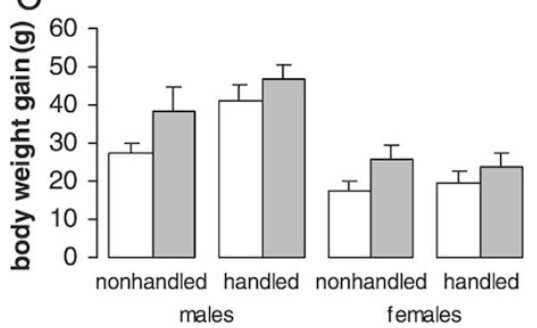

Figure 3. Total caloric intake, caloric efficiency, and body weight gain during long-term exposure in handled and nonhandled male and female rats. Chow ( $\square$ ); chow + chocolate $(\square)$. Data are expressed as mean \pm SEM. $(A)$ Total kilocalories consumed. $(B)$ Caloric efficiency, calculated as body weight gain per kilocalories consumed. $(C)$ Body weight gain, three to four cages per group. Three-way ANOVA showed greater caloric intake $(p<0.001)$ and body weight gain $(p=0.019)$ in groups receiving chocolate. Handled males had an increased caloric efficiency $(p=0.050)$.
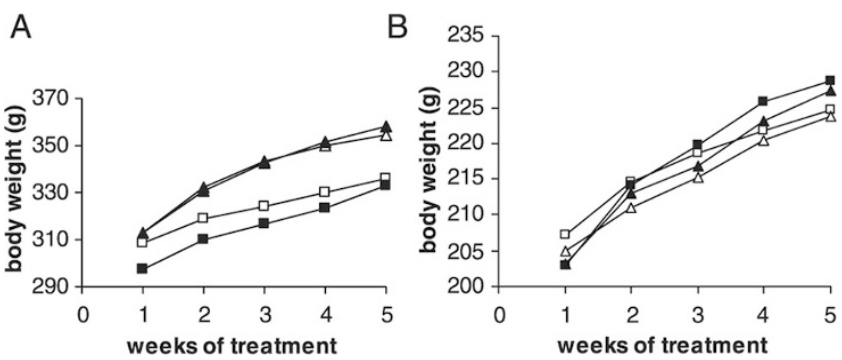

Figure 4. Body weight during chronic chocolate exposure in handled and nonhandled adult rats. $\mathrm{NH}$ chow $(\square)$; $\mathrm{NH}$ chocolate $(\square)$; $\mathrm{H}$ chow $(\Delta)$; $\mathrm{H}$ chocolate $(\mathbf{\Lambda})$. (A) Mean body weight for males, 11-13 animals per group. $(B)$ Mean body weight for females, 7-11 animals per group. Repeated-measures ANOVA showed an effect of gender, diet, and interactions between time $\times$ group, time $\times$ gender, time $\times$ diet, and time $\times$ gender $\times$ group $(p<0.050)$.

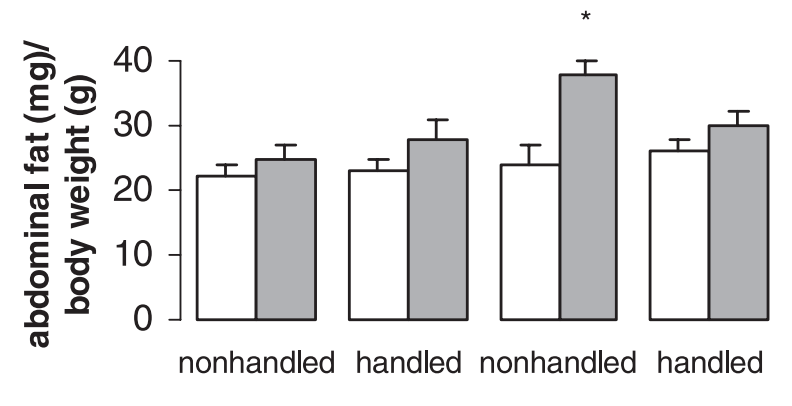

males

females

Figure 5. Abdominal fat deposition, expressed as mean \pm SEM of abdominal fat/body weight; $11-13$ per group for males and 9-12 per group for females. Chow $(\square)$; chow + chocolate $(\square)$. Three-way ANOVA showed effects of diet $(p<0.001)$, gender $(p=0.002)$, and an interaction between group $\times$ diet $\times$ gender $(p=0.05)$. *Significantly different from all other groups (Duncan's multiple range test, $p=0.05$ ).

levels $(p=0.024)$, without there being a main effect of group $(p=0.159)$ or gender $(p=0.146)$.

Plasma glucose, insulin, and corticosterone levels. Females had higher glucose levels than males (three-way ANOVA, $p<0.001$, six to seven per group). There was no effect of diet $(p=0.840)$ or group $(p=0.380)$, nor were there any interactions.

Basal corticosterone levels were not affected by handling, gender, or diet ( $p>0.05$, five to seven per group), nor were there any interactions between these factors. Insulin levels, however, were lower in females than in males $(p=0.012$, six to seven per group), without there being an effect of the neonatal handling, diet, or interactions $(p>0.05$ for handling

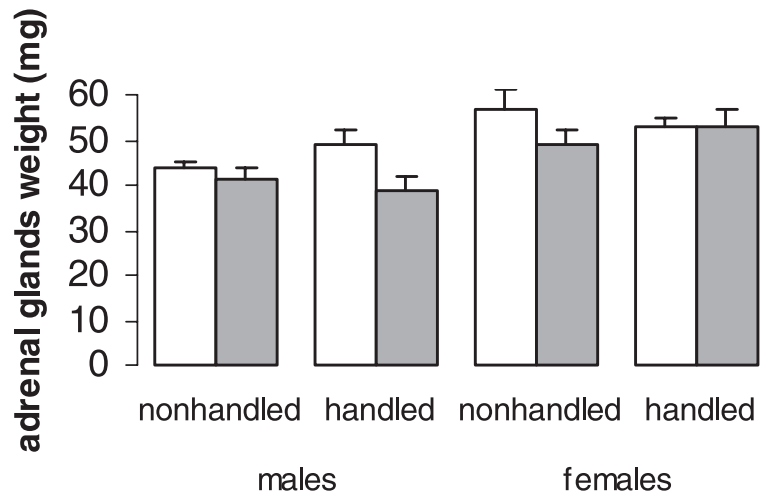

Figure 6. Adrenal glands weight, expressed as mean \pm SEM; 11-13 per group for males and 7-11 per group for females. Chow ( $\square)$; chow + chocolate $(\square)$. Three-way ANOVA showed an effect of the diet $(p<0.02)$ and gender $(p<0.001)$.

and diet) (Table 4). A three-way ANOVA of the glucose/ insulin ratio data showed a significant effect of gender $(p=$ $0.001)$, without any effect of handling, diet, or interactions $(p>0.05)$. Additionally, a three-way ANOVA of the HOMA-IR (homeostasis model assessment insulin resistance index) to assess insulin resistance showed no significant effect of gender, handling, diet, or interactions $(p>0.05$; data not shown).

\section{DISCUSSION}

In this study, neonatal handling was associated with an increased consumption of chocolate in adulthood, when this food was offered for a brief duration of time. However, when exposed long term to chocolate, handled males exhibited an important reduction in consumption over time, reaching the amount consumed by nonhandled males. Handled males also had a more salient increase in body weight, greater caloric efficiency, and lower TG levels without there being any alteration in abdominal fat. Nonhandled females that were exposed to chocolate long term had higher abdominal fat deposition in comparison with handled females. Female rats exhibited higher total cholesterol, higher glucose levels, and lower insulinemia when compared with males. Animals receiving chocolate also had a reduction in the adrenal gland weight.

Previous reports have shown that during food restriction and over short periods of exposure, handled animals consume more palatable food than nonhandled animals (9). When there was long-term exposure to sweet or lard-enriched diets, how- 
Table 3. Plasma lipids $(\mathrm{mg} / \mathrm{dL})$ of handled and nonhandled rats receiving standard chow with or without chocolate ad libitum

\begin{tabular}{|c|c|c|c|c|}
\hline & Group & $\mathrm{CHO}$ & HDL-C & TAG \\
\hline \multirow{4}{*}{ Males } & Chow only & $43.4 \pm 2.5$ & $26.3 \pm 2.9$ & $118.1 \pm 16.6$ \\
\hline & Chow + choco & $42.4 \pm 1.5$ & $26.6 \pm 4.4$ & $196.1 \pm 25.7 *$ \\
\hline & Chow only & $39.3 \pm 1.7$ & $24.4 \pm 3.5$ & $76.3 \pm 6.8$ \\
\hline & Chow + choco & $39.8 \pm 1.7$ & $24.6 \pm 3.6$ & $135.1 \pm 10.0$ \\
\hline \multirow[t]{4}{*}{ Females } & Nonhandled & & & \\
\hline & Handled & & & \\
\hline & Chow only & $47.2 \pm 5.1$ & $24.0 \pm 5.2$ & $101.2 \pm 8.8$ \\
\hline & Chow + choco & $47.8 \pm 2.1$ & $33.0 \pm 4.2$ & $133.2 \pm 27.8$ \\
\hline
\end{tabular}

Data are shown as mean \pm SEM; 11-13 per group for males and 7-11 per group for females. CHO, cholesterol; HDL-C, high-density lipoprotein cholesterol; TAG, triacylglycerol. Chocolate consumption increased TAG levels in male and female rats (three-way ANOVA, effect of diet, $p<0.001$ ). In males, the neonatal handling procedure decreased TAG levels (three-way ANOVA, interaction between group and gender, $p=0.024$ ). Females presented higher total cholesterol levels than males (three-way ANOVA, effect of gender, $p<0.001$ ). * Significantly different from all other groups (Duncan's multiple range test, $p<0.05$ ).

Table 4. Fasting plasma glucose $(\mathrm{mg} / \mathrm{dL})$, insulin $(\mu \mathrm{g} / \mathrm{L})$, and corticosterone levels $(\mathrm{ng} / \mathrm{mL})$ of handled and nonhandled rats receiving standard chow with or without chocolate ad libitum

\begin{tabular}{|c|c|c|c|c|}
\hline & Group & Glucose & Insulin & Corticosterone \\
\hline \multirow[t]{5}{*}{ Males } & Nonhandled & & & \\
\hline & Chow only & $130.59 \pm 6.3$ & $1.86 \pm 0.3$ & $136.04 \pm 38.6$ \\
\hline & Chow + choco & $126.22 \pm 4.7$ & $1.85 \pm 0.2$ & $170.67 \pm 32.8$ \\
\hline & Chow only & $139.25 \pm 6.4$ & $1.74 \pm 0.4$ & $182.4 \pm 47.7$ \\
\hline & Chow + choco & $127.00 \pm 2.3$ & $2.02 \pm 0.3$ & $177.90 \pm 18.1$ \\
\hline \multirow[t]{4}{*}{ Females } & Nonhandled & & & \\
\hline & Handled & & & \\
\hline & Chow only & $150.43 \pm 9.2$ & $1.37 \pm 0.4$ & $190.47 \pm 47.1$ \\
\hline & Chow + choco & $157.78 \pm 8.2$ & $1.25 \pm 0.3$ & $172.17 \pm 39.2$ \\
\hline
\end{tabular}

Data are shown as mean \pm SEM; six to seven per group (glucose), five to seven per group (corticosterone), six to seven per group (insulin). Females presented higher glucose and lower insulin levels than males (three-way ANOVA, effect of gender, $p<0.001$ for glucose and $p=0.012$ for insulin).

ever, no differences were found between handled and nonhandled animals (17). To our knowledge, this is the first investigation in which handled and nonhandled animals were exposed long term to a highly palatable diet rich in both sugar and fat, such as chocolate. During long-term exposure to this type of diet, all animals demonstrated a slow decrease in chocolate consumption over time. This decrease was expected in control animals because overconsumption of highly caloric food is known to evoke physiologic responses to adjust caloric intake when molecular markers related to energy expenditure and food intake are altered (18). Handled male rats showed the greatest decrease in chocolate consumption during the first week of treatment, suggesting a diminishing chocolate preference in these animals. Eventually both handled and nonhandled animals displayed similar levels of consumption. These changes in chocolate consumption may reflect an adaptation of the animals to this diet when offered long term. Despite this reduction in consumption, all groups still preferred chocolate to standard lab chow because more than $50 \%$ of kilocalories consumed were derived from chocolate, and total kilocalories ingested were increased in animals offered chocolate.

All groups increased body weight over time; however, the body weight gain differed between the groups. Males gained more weight compared with females, as expected, and animals receiving chocolate also gained more weight because their caloric intake was higher. Neonatally handled animals gained the most weight over time, the effect being most evident in males. This was an interesting observation because total caloric intake was not different between handled and nonhandled animals; therefore, the increased weight gain in handled animals is probably related to their increased caloric efficiency. This result agrees with another report in which neonatal handling increased body weight and caloric efficiency in male mice (19).

Chocolate consumption increased abdominal fat deposition, especially in females. Neonatal handling, however, attenuated the increase in abdominal fat deposition in females exposed to chocolate. Other studies have demonstrated that both neonatal handling and maternal care have an important role in the development of neuroendocrine function, decreasing HPA axis responses to acute stress in adulthood $(7,20)$. In this study, we demonstrated that neonatal handling, which is known to increase maternal care (21), modulates the metabolic profile of animals that are challenged with long-term exposure to a highly palatable diet. Handled animals gain significantly less abdominal fat than nonhandled animals when exposed long term to chocolate.

The mechanisms by which handling induces this protective influence on the development of abdominal fat deposition are 
currently unknown. One possible avenue of investigation involves the role of glucocorticoids in the development of abdominal obesity because glucocorticoids are known to have direct actions on adipose tissue (22). Neonatally handled animals, which have been shown to have a more efficient negative feedback $(23,24)$, could respond differently to the acute surge of glucocorticoids that occur after a meal (25). Furthermore, tissue sensitivity to glucocorticoids may be involved in this effect. Further studies will be designed to elucidate these questions.

Another possibility could be an alteration in metabolic regulation. A differential sympathoadrenal function has been reported in these handled animals (17) as well as an increased abdominal fat content in neonatally handled animals, which disagrees with current and previous findings (16). However, differences in rat strains and protocols for neonatal handling may influence these inconsistencies.

The adrenal gland weight was decreased in both groups receiving chocolate. This decreased adrenal weight agrees with the concept of "comfort food" proposed by Dallman et al. (26), in which highly caloric, highly palatable diets are able to decrease HPA axis activity $(26,27)$. There was no difference, however, in basal corticosterone levels between the different groups on the two diets.

Biochemical measurements indicated that neonatally handled male rats had decreased TG plasma levels. This was an interesting finding because exposure to the highly palatable diet increased triglyceride levels in all the animals except for handled males whose TG levels were similar to those of control animals. The metabolic profile exhibited by handled male animals, including higher body weight without alteration in the abdominal fat deposition, increased caloric efficiency, and decreased plasma TG levels, suggests a particular metabolic response concerning energy storage and expenditure when exposed long term to a highly palatable diet.

Plasma total cholesterol levels were increased in females, whereas neonatal handling and diet exposure had no influence on this measure. This finding is in agreement with other reports in the literature $(28,29)$. HDL cholesterol levels and the total cholesterol:HDL ratio, which is related to increased cardiovascular risk, were similar across the different groups. Conversely, $30 \mathrm{~d}$ of chocolate exposure was enough to lead to a significantly increased abdominal fat deposition in nonhandled females. Thus, future studies will address how neonatal handling might mediate the development of risk factors for cardiovascular disease.

In females, blood glucose levels were increased compared with males. Conversely, insulin levels were lower in females. These gender effects on insulin have been observed in other studies using rats $(29,30)$; however, blood glucose concentrations usually tend to be similar between males and females $(30,31)$. Previous studies have shown enduring effects of prenatal manipulations on HPA axis function and cardiovascular risk factors; these effects tended to be gender specific $(31,32)$. Here, we suggest that the outcome of a postnatal manipulation can have a sex-specific influence on the metabolic profile of animals chronically exposed to a palatable diet.
In conclusion, adult animals handled during the neonatal period showed an increased consumption of palatable food when exposed to this type of diet for short periods of time. This difference in consumption abated when the animals were exposed long term to this diet. Handled animals had lower TG levels and increased body weight and caloric efficiency. Moreover, neonatal handling induced a sex-specific protective influence on abdominal fat deposition in those females that were chronically exposed to chocolate. All these results suggest a specific metabolic pattern related to energy storage and expenditure in animals handled during the neonatal period. Although these findings suggest that neonatal handling may reduce the risk of metabolic syndrome in adulthood, the effects of handling tended to be gender dependent.

\section{REFERENCES}

1. Wright CM, Parkinson KN, Drewett RF 2006 How does maternal and child feeding behavior relate to weight gain and failure to thrive? Data from a prospective birth cohort. Pediatrics 117:1262-1269

2. Burdette HL, Whitaker RC, Hall WC, Daniels SR 2006 Maternal infant-feeding style and children's adiposity at 5 years of age. Arch Pediatr Adolesc Med 160:513-520

3. Faith MS, Heshka S, Keller KL, Sherry B, Matz PE, Pietrobelli A, Allison DB 2003 Maternal-child feeding patterns and child body weight: findings from a populationbased sample. Arch Pediatr Adolesc Med 157:926-932

4. Zhang TY, Bagot R, Parent C, Nesbitt C, Bredy TW, Caldji C, Fish E, Anisman H, Szyf M, Meaney MJ 2006 Maternal programming of defensive responses through sustained effects on gene expression. Biol Psychol 73:72-89

5. Champagne F, Diorio J, Sharma S, Meaney MJ 2001 Naturally occurring variations in maternal behavior in the rat are associated with differences in estrogen-inducible central oxytocin receptors. Proc Natl Acad Sci U S A 98:12736-12741

6. Pruessner JC, Champagne F, Meaney MJ, Dagher A 2004 Dopamine release in response to a psychological stress in humans and its relationship to early life maternal care: a positron emission tomography study using [11C] raclopride. J Neurosci 24:2825-2831

7. Levine S, Haltmeyer GC, Karas GG, Denenberg VH 1967 Physiological and behavioral effects of infantile stimulation. Physiol Behav 2:55-59

8. Padoin MJ, Cadore LP, Gomes CM, Barros HM, Lucion AB 2001 Long-lasting effects of neonatal stimulation on the behavior of rats. Behav Neurosci 115:13321340

9. Silveira PP, Portella AK, Clemente Z, Bassani E, Tabajara AS, Gamaro GD, Dantas G, Torres IL, Lucion AB, Dalmaz C 2004 Neonatal handling alters feeding behavior of adult rats. Physiol Behav 80:739-745

10. Fichter MM, Pirke KM, Pollinger J, Wolfram G, Brunner E 1990 Disturbances in the hypothalamo-pituitary-adrenal and other neuroendocrine axes in bulimia. Biol Psychiatry 27:1021-1037

11. Kaye WH, Rubinow D, Gwirtsman HE, George DT, Jimerson DC, Gold PW 1988 CSF somatostatin in anorexia nervosa and bulimia: relationship to the hypothalamic pituitary-adrenal cortical axis. Psychoneuroendocrinology 13:265-272

12. Pecoraro N, Gomez F, Dallman MF 2005 Glucocorticoids dose-dependently remodel energy stores and amplify incentive relativity effects. Psychoneuroendocrinology 30:815-825

13. Boullu-Ciocca S, Dutour A, Guillaume V, Achard V, Oliver C, Grino M 2005 Postnatal diet-induced obesity in rats upregulates systemic and adipose tissue glucocorticoid metabolism during development and in adulthood: its relationship with the metabolic syndrome. Diabetes 54:197-203

14. Brunner EJ, Hemingway H, Walker BR, Page M, Clarke P, Juneja M, Shipley MJ, Kumari M, Andrew R, Seckl JR, Papadopoulos A, Checkley S, Rumley A, Lowe GD, Stansfeld SA, Marmot MG 2002 Adrenocortical, autonomic, and inflammatory causes of the metabolic syndrome: nested case-control study. Circulation 106:26592665

15. Duclos M, Marquez Pereira P, Barat P, Gatta B, Roger P 2005 Increased cortisol bioavailability, abdominal obesity, and the metabolic syndrome in obese women. Obes Res 13:1157-1166

16. Silveira PP, da Silva Benetti C, Ayres C, Pederiva FQ, Portella AK, Lucion AB, Dalmaz C 2006 Satiety assessment in neonatally handled rats. Behav Brain Res 173:205-210

17. Young JB 2000 Effects of neonatal handling on sympathoadrenal activity and body composition in adult male rats. Am J Physiol Regul Integr Comp Physiol 279:R1745-R1752

18. Archer ZA, Rayner DV, Duncan JS, Bell LM, Mercer JG 2005 Introduction of a high-energy diet acutely up-regulates hypothalamic cocaine and amphetamineregulated transcript, Mc4R and brown adipose tissue uncoupling protein-1 gene expression in male Sprague-Dawley rats. J Neuroendocrinol 17:10-17

19. Loizzo A, Loizzo S, Galietta G, Caiola S, Spampinato S, Campana G, Seghieri G, Ghirlanda G, Franconi F 2006 Overweight and metabolic and hormonal parameter disruption are induced in adult male mice by manipulations during lactation period. Pediatr Res 59:111-115 
20. Liu D, Diorio J, Tannenbaum B, Caldji C, Francis D, Freedman A, Sharma S, Pearson D, Plotsky PM, Meaney MJ 1997 Maternal care, hippocampal glucocorticoid receptors, and hypothalamic-pituitary-adrenal responses to stress. Science 277:1659-1662

21. Pryce CR, Bettschen D, Feldon J 2001 Comparison of the effects of early handling and early deprivation on maternal care in the rat. Dev Psychobiol 38:239-251

22. Masuzaki H, Paterson J, Shinyama H, Morton NM, Mullins JJ, Seckl JR, Flier JS 2001 A transgenic model of visceral obesity and the metabolic syndrome. Science 294:2166-2170

23. Meaney MJ, Aitken DH, Viau V, Sharma S, Sarrieau A 1989 Neonatal handling alters adrenocortical negative feedback sensitivity and hippocampal type II glucocorticoid receptor binding in the rat. Neuroendocrinology 50:597-604

24. Ader R, Grota LJ 1969 Effects of early experience on adrenocortical reactivity. Physiol Behav 4:303-305

25. Follenius M, Brandenberger G, Hietter B 1982 Diurnal cortisol peaks and their relationships to meals. J Clin Endocrinol Metab 55:757-761

26. Dallman MF, Pecoraro N, Akana SF, La Fleur SE, Gomez F, Houshyar H, Bell ME, Bhatnagar S, Laugero KD, Manalo S 2003 Chronic stress and obesity: a new view of "comfort food". Proc Natl Acad Sci U S A 100:11696-11701
27. Pecoraro N, Reyes F, Gomez F, Bhargava A, Dallman MF 2004 Chronic stress promotes palatable feeding, which reduces signs of stress: feedforward and feedback effects of chronic stress. Endocrinology 145:3754-3762

28. Nevala R, Vaskonen T, Vehniainen J, Korpela R, Vapaatalo H 2000 Soy based die attenuates the development of hypertension when compared to casein based diet in spontaneously hypertensive rat. Life Sci 66:115-124

29. Slotkin TA, Brown KK, Seidler FJ 2005 Developmental exposure of rats to chlorpyrifos elicits sex-selective hyperlipidemia and hyperinsulinemia in adulthood. Environ Health Perspect 113:1291-1294

30. Sugden MC, Holness MJ 2002 Gender-specific programming of insulin secretion and action. J Endocrinol 175:757-767

31. O'Regan D, Kenyon CJ, Seckl JR, Holmes MC 2004 Glucocorticoid exposure in late gestation in the rat permanently programs gender-specific differences in adult cardiovascular and metabolic physiology. Am J Physiol Endocrinol Metab 287:E863-E870

32. Liu L, Li A, Matthews SG 2001 Maternal glucocorticoid treatment programs HPA regulation in adult offspring: sex-specific effects. Am J Physiol Endocrinol Metab 280:E729-E739 